\title{
CORPORATE SOCIAL RESPONSIBILITY DALAM BINGKAI SYARIAH
}

\author{
Arditi Annisa $\mathbf{H}^{\mathbf{1}}$, Nuraini $\mathbf{A}^{* 2}$ \\ ${ }^{1,2}$ Program Studi Akuntansi Fakultas Ekonomi dan Bisnis Universitas Syiah Kuala \\ e-mail: nurainia@ unsyiah.ac.id ${ }^{2}$
}

\section{* Corresponding Author}

\begin{abstract}
Abstrak
Research in corporate social responsibility (CSR) has long been established yet there are still new dimensions for its discussion within the Islamic perspective. This study undertakes the investigation of CSR within the Islamic banking industry utilizing the Shariah Enterprise Theory (SET). It seeks to identify whether the factors of size, profitability and shariah compliance may play role in the disclosure of CSR by Islamic banks in Indonesia. All registered Islamic banks in Indonesia publishing their annual report for the period of 2011-2016 were employed as samples of this study. The findings demonstrated that some of the sampled banks have provided extensive and informative disclosure of CSR. Simulteanously the three studied variables consisting of size, profitability and shariah compliance were found to influence the CSR disclosure. Nevertheless, partially while bank size and profitability were found to influence the CSR disclosure yet there was no influence of shariah compliance towards CSR disclosure. This gives an interesting insight for further examination in future studies.
\end{abstract}

Keywords: Corporate Social Responsibility, Shariah Enterprise Theory, Firm Size, Profitability, and Shariah Compliance

\section{Pendahuluan}

Corporate Social Responsibility (CSR) sudah menjadi hal yang populer dalam dunia ekonomi dan bisnis. CSR sendiri sudah menjadi trend tersendiri pada perusahaan-perusahaan bisnis di dunia baik perusahaan syariah maupun non syariah. Hal ini dibenarkan oleh Olifia (Economic Review News, 2017) menyatakan bahwa telah terselenggaranya ajang penghargaan yang berkaitan dengan perusahaanperusahaan yang mengimplementasikan kegiatan sosial secara baik. Perusahaan yang mengimplementasi praktek CSR secara baik di Indonesia mendapatkan apresiasi penghargaan tertinggi baik dalam kategori Tbk (Terbuka) ataupun Private

Tanggung jawab sosial menjadi salah satu revolusi atau perubahan baru dalam bisnis yang akan terus berlanjut sepanjang tahun (Jeffrey Hayzeltt, 2016). Sejalan dengan perkembangan zaman, pertumbuhan yang dialami CSR di Indonesia semakin meningkat menjadi lebih baik melihat dari segi kualitas maupun kuantitas. Hal tersebut terlihat dari semakin banyaknya perusahaan-perusahaan yang melaporkan kegiatan CSR dalam laporan tahunan
Di Indonesia pelaksanaan CSR diatur melalui UU No. 25 pasal 15 tahun 2007 tentang Penanaman Modal. Undang-undang ini mengatur kewajiban penanaman modal untuk melaksanakan tanggung jawab sosial perusahaan, serta konsekuensi apabila penanam modal tidak melaksanakan kewajiban tersebut dapat dikenakan sanksi. Sementara terkait pengungkapan CSR diatur dalam UU No. 40 Pasal 66 Tahun 2007 tentang Perseroan Terbatas. Dalam undang-undang No. 40 ini menyebutkan beberapa informasi harus dimuat dalam laporan tahunan, dan laporan tanggung jawab sosial berserta lingkungan harus di ungkapkan.

Konsep CSR juga berkembang dalam konteks ekonomi Islam, bukan hanya di ekonomi konvensional. Konsep CSR sendiri sebenarnya lebih sesuai pada perusahaan yang segala kegiatan bisnisnya dijalankan berdasarkan dengan konsep syariaah.

Perbankan syariah merupakan institusi yang berperan dalam pengimplementasi pengungkapan tanggung jawab sosial di dunia bisnis. Eksistensi perbankan syariah sebagai pelopor dalam pengungkapan CSR dalam konteks lembaga keuanga sudah mendapat pengakuan pada tingkat nasional 
maupun internasional, dimana perbankan syariah harus menjadi best making untuk lembaga keuangan dalam mengerakkan program-program sosial (Samsiyah, 2013)

Perkembangan asset perbankan syariah di dunia cukup mengagumkan, berdasarkan data yang di himpun oleh Islamic Financial Services Board IFSB tahun 2015 pada 31 Negara, menunjukkan bahwa asset perbankan syariah tumbuh mencapai 1,49 triliun dolar AS. Sejalan dengan perkembangan assetnya, perbankan syariah juga menuai kritik dari berbagai pihak. Perbankan syariah dinilai belum memberikan kontribusi maksimal dalam penguatan keadilan social dan ekonomi bagi masyarakat. Praktek perbankan syariah juga di nilai hanya sekedar memenuhi kriteria dalam kontrak dibandingkan dengan tujuan utama dari perbankan syariah yaitu mewujudkan masyarakat yang adil dan menurunkan masyarakat yang kurang mampu (Nienhaus, 2011).

Menurut Erwin FS (Charm Indonesia, 2004) Terdapat keunikan pada CSR yang dilakukan oleh bank syariah yaitu masyarakat mendapatkan banyak manfaat dari CSR ini dan tidak mengalami ekternalitas dari keberadaan bank syariah. Bank syariah berperan sebagai sebuah institusi, ikut serta mendorong implementasi tujuan syariah (maqashid). Perkembangan dan peran perbankan syariah dalam perekonomian semakin baik. Hal tersebut membuat perbankan syariah membutuhkan sebuah standar penilaian untuk melihat bagaimana praktek CSR agar sesuai dengan tujuan dan karakteristik perbankan syariah, dimana perbankann syariah itu sendiri merupakan instansi yang mengimplementasikan kegiatan usahanya berdasarkan prinsip-prinsip syariah.

Penerapan CSR pada perbankan syariah di lihat dalam bingkai Shariah Enterprise Theory (SET). Theory ini dipandang tepat dan layak dalam menilai tingkat penerapan CSR pada perbankan syariah, karena prinsip-prinsip atau nilai yang terkandung dalam SET sesuai dengan perbankan syariah.

Shariah Enterprise Theory adalah teori yang diinternalisasi dari Enterprise Theory, yaitu teori yang dianggap tepat dalam akuntansi syariah, hanya saja teori ini belum memiliki konsep tauhid didalamnya. Meskipun demikian Slamet (2001) menyatakan bahwa Enterprise Theory dianggap tepat karena didalamnya tekandung nilai kebenaran, keadilan, kejujuran, pertanggungjawaban, dan amanah. Konsep utama yang ada didalam Shariah Enterprise Theory adalah dimana Allah menjadi sumber amanah yang paling utama, sementara kepemilikan oleh para stakeholders merupakan sumber daya yang pertanggungjawabannya juga berdasarkan ketentuan dari Allah.

Dalam pengungkapan CSR, ada beberapa hal yang dapat mempengaruhi keputusan yang diambil dalam melaporkan tanggung jawab sosial ke dalam laporan tahunan salah satunya adalah ukuran perusahaan. Febriyani et al., (2013) menemukan bahwa ukuran perusahaan, profitabilitas dan kepatuhan syariah secara signifikan mempengaruhi tingkat pengungkapan Islamic Social Reporting (ISR). Demikian juga (Lestari, 2013) dalam penelitiannya juga membuktikan bahwa ukuran perusahaan dan profitabilitas brpengaruh secara sgnifikan terhadap tingkat pengungkapan ISR.

Konsep CSR telah diuji dalam penelitian sebelumnya, namun masih terbatas pada penelitian factor apa yang mendorong perusahaan untuk menggungkapkan CRS dalam perspektif syariah. Adapun penelitian yang menguji konsep syariah dalam perspektif syariah yaitu, Mansur (2012). Hasil penelitian ini menyatakan bahwa praktek pengungkapan CSR masih bersifat sukarela dan belum memenuhi konsep Shariah Enterprise Theory. Maka dari itu, penelitian yang terkait dengan pelaporan CSR berdasarkan Shariah Enterprise Theory masih perlu dikembangkan, agar implementasi dalam pengungkapkan CSR pada perbankan syariah dapat dilakukan secara berkesinambungan.

\section{Kajian Teoritis dan Pengembangan Hipotesis Corporate SocialResponsibility (CSR)}

Konsep CSR banyak didefinisikan oleh para pakar, Kotler and Lee (2005) menyatakan CSR merupakan suatu aktivitas dan kemauan perusahaan, sementara Untung (2008) berpendapat bahwa CSR merupakan komitmen perusahaan dalam mengembangkan ekonomi yang berkelanjutan dengan memperhatikan aspek sosial perusahaan.

Bagi umat Islam, etika syariah sangat melekat dengan kegiatan bisnis termasuk bisnis perbankan. Bank syariah merupakan perusahaan atau instansi yang mengimplementasikan kegiatan usahanya dengan dasar nilai-nilai Islam. Aktivitas CSR sendiri sudah menjadi hal yang lazim di perbankan syariah, karena didalam ajaran Islam sangat dianjurkan untuk 
melakukan kegiatan sosial. Maka dari itu, menurut Yusuf (2010) kegiatan CSR bukanlah sesuatu hal yang baru, CSR sendiri juga tersuarat didalam Al-Qur'an (Q.S Al-Baqarah 205, Q.S Al-A'raaf, Al Taqabun 16).

Pengungkapan pelaksanaan CSR penting dilakukan agar para stakeholder bank syariah mengetahui dengan pasti pencapaian pelaksanaan program-progam CSR. Hal ini penting karena, mengingat bank syariah tidak hanya melakukan pencapaian kinerja keuangan tetapi juga kinerja sosial (Wahyuni, 2013). Menurut (Meutia et al., 2010) pelaporan CSR merupakan cara bagi perusahaan sebagai alat komunikasi dengan para stakeholder bahwa perusahaan telah memperhatikan lingkungan sosial dan menginformasikan bagaimana dampak aktivitas-aktivita yang telah dilakukan oleh perusahaan.

\section{Shariah Enterprise Theory (SET)}

Shariah Enterprise Theory adalah sebuah konsep yang lahir dari Enterprise Theory yang telah diinternalisasi dengan kandungan nilai Islam. Dengan adanya SET dapat memperoleh legitimasi untuk memasukkan beberapa pemahaman antara lain konsep zakat, konsep pertanggungjawaban, konsep kepemilikan dalam Islam dan konsep keadilan Ilahi.

\section{Value-added Statement (Laporan Nilai} Tambah) juga tersaji didalam SET menjadi salah satu laporan keuangan. Pada dasarnyaValue-added Statement adalah laporan Laba-Rugi, namun Laporan ini tidak bisa dipersamakan dengan laporan laba rugi. Laporan value added statement adalah laporan yang berfokus atau menitikberatkan pada alokasi nilai tambah yang dikelola oleh perusahaan akan diberikan kepada mereka yang berhak menerimanya (beneficiaries). Laporan value added statement juga memberikan informasi tentang nilai alokasi kepada pihak-pihak yang mempunyai hak untuk menerimanya.

Berdasarkan Slamet (2001) menyatakan bahwa alokasi nilai tambah kepada penerima mamfaat atau beneficiaries dapat di salurkan kepada: (1) pihak yang berhubungan langsung dengan perusahaan (direct stakeholders) dan (2) pihak yang tidak berhubungan langsung dengan perusahaan (indirect Stakeholders). Adapaun pihak-pihal tersebut adalah: Pemegang Saham, manajemen, karyawan, kreditur, Pemasok,
Pemerintah, dan masyarakat mustahiq (penerima zakat, infaq dan shadaqah) dan lingkungan alam

Pengungkapan tanggung jawab social perusahaan perbankan syarian dalam perspektif shariah enterprise theory merupakan bentuk akuntabilitas pengelola perusahaan/ bank kepada sang khalid Allah SWT. Kemudian yang kedua yaitu bahwa pengungkapan tanggung jawab sosial juga menjadi bagian dari akuntabilitas antara sesama manusia. Tujuan pengungkapan tanggungjawab social perusahaan adalah untuk memberikan informasi terkait pengelola perusahaan dalam aspek syariah kepada stake dan stock holder. Ketiga kharakteristik pengungkapan tanggungjwab sosial adalah mandatory. Keempat bahwa dimensi spritual dan material yang memiliki kaitan dengan kepentingan para pemangku kepentingan harus tercakup dalam infomasi CSR, dan yang terakhir informasi-informasi yang ada dalam pengungkapan tanggung jawab sosial harus kualitatif dan kuantitatif.

Dalam theory agency menjelaskan tingkat keterbukaan suatu perusahaan berkaitan dengan ukuran perusahaan seperti total asset perusahaan (Belkaoui, 2001). Dalam banyak kajian menyebutkan besar kecilnya ukuran perusahaan merupakan hal menjadi penentu untuk melakukan pengungkapan atau transparansi. Perusahaan yang besar biasanya cenderung melakukan pengukapan.

Menurut Santosoet. al (2017) ukuran perusahaan berpengaruh pada luasnya pengungkapan informasi terkait lingkungan. Dalam praktek nya industry perbankan tidak berhubungan dengan penggunaan sumber daya alam, atau energy, akan tetapi lembaga perbankan harus focus pada aktivitas yang peduli dengan lingkungan. Dan praktek pengungkapan informasi yang berkaitan dengan lingkungan sudah mulai di lakukan.

Ukuran perusahaan berpengaruh terhadap Islamic Social Reporting Disclosure (Setiawan et al., 2016). Hasil penelitian ini menjelaskan bahwa ada kaitannya antara ukuran perusahaan dengan keputusan perusahaan untuk mengungkapan informasi aktivitas social dan lingkungan. Keputusan pengungkapan tanggung jawab social berkaitan dengan besar kecilnya suatu perusahaan. Perusahaan besar lebih cenderung mengungkapkan lebih banyak informasi di bagian naratif laporan sementara. 
$\mathrm{H}_{1}$ : Ukuran perusahaan berpengaruh terhadap tingkat pengungkapan tanggungjawab sosial.

Dalam perspektif Islam, menghasilkan laba atau tidak perusahaan harus mengungkapkan informasi secara spesifik. Laba merupakan salah satu faktur yang mempengaruhi going concern suatu perusahaan. Dalam banyak penelitian banyak peneliti menghubungkan profitabilitas dengan tingkat pengungkapan social perusahaan. Hasil penelitian Purnasanti et al., (2014) mengatakan bahwa kemampuan perusahaan menghasilkan laba akan menyebabkan perusahaan akan mengungkapkan informasi keuangan dan non keuangan dalam laporan keuangan.

$\mathrm{H}_{2}$ : ROE berpengaruh terhadap tingkat pengungkapan tanggung jawab sosial.

Pengungkapan tanggung jawab social perusahaan dalam aspek syariah harus memenuhi nilai-nilai syariah. Perbedaan yang mendasar pengungkapan tanggung jawab social antara system konvesional dengan system syariah adalah pada aspek pemenuhan nilai-nilai syariah. Ansori (2001) mengemukakan bahwa aspek pemenuhan nilai-nilai syariah adalah indicator pengungkapan dalam menjamin kepatuhan bank syariah terhadap prinsip syariah.

Kepatuhan syariah merupakan bentuk tanggungjawab bank melalui disclosure kepatuhan syariah. Tinggi rendahnya kepatuhan syariah berdampak pada belum oprimalnya perhatian bank dalam kegiatan social, tingkat kepatuhan syariah yang tinggi maka menunjukkan bahwa bank perduli terhadap lingkungan dan aktivitas social (Febriayani, 2013)

$\mathrm{H}_{3}$ : Kepatuhan Syariah berpengaruh terhadap tingkat pengungkapan tanggung jawab sosial.

\section{Metode Penelitian}

Penelitian ini dilakukan pada Bank Umum Syariah yang telah daftar pada Otoritas Jasa Keuangan (OJK) selama 5 periode yaiu 2011 sampai dengan 2016. Unit analisis yaitu bank syariah. Data yang digunakan adalah data sekunder berupa laporan keuangan yang dapat diakses pada masing-masing website BUS terkait. Pengujian hipotesis menggunakan regresi linier berganda dengan SPSS.

\section{Pengukuran Variabel}

Corporate Social Responsibility Disclosure yang disajikan dalam bentuk data oleh perusahaan berkaitan dengan aktivitas atau kegiatan sosial dan berdasarkan SET. Selanjutnya pengungkapan CSR dilakukan identifikasi dengan menggunakan indeks SET. Pengukuran indeks SET dalam penelitian ini mengacu Meutia et al. (2010); Mansur (2012); Wahyuni (2013) dan Febriany et al. (2014).Dalam melakukan idetinfikasi, peneliti melakukan analisis secara keseluruhan dengan menggunakan metode skoring berdasarkan indeks SET. Indeks set terdiri Akuntabilitas kepada Allah SWT, Akuntabilitas terhadap nasabah, karyawan, komunitas dan akuntabilitas kepada alam. Berdasarkan 5 indikator indeks SET tersebut dikembangkan menjadi 43 item pertanyaan. Penilaian di lakukan dengan skoring nilai 1 jika di unggkapkan dan 0 jika tidak di ungkapkan. Adapun formulanya sebagai berikut:

$$
\text { SET }=\frac{\text { jumlah point yang diungkapkan }}{\text { jumlah skor maksimal }} .100 \%
$$

Ukuran Perusahaan diukur melalui log natural of Total Assets yang peroleh dari laporan keuangan akhir tahun perusahaan. Size $=$ Ln (Total Aset). Sementara profitabilitas di ukur dengan ROE (Return On Equity)

$$
R O E=\frac{\text { Laba setelah pajak }}{\text { Total ekuitas }}
$$

Tingkat kepatuhan syariah dilihat dari porsi pembiayaan non Murabahah yaitu perbandingan antara porsi Murabahah dengan total pembiayaan dengan rumuskan sebagai berikut:

\section{Porsi Pembiayaan Non Murabahah}

$$
=\frac{\text { Porsi Murabahah }}{\text { Total Pembiayaan }}
$$

\section{Hasil dan Pembahasan Statistik Deskriptif}

Pada bagian ini akan dilakukan analisis perhitungan berdasarkan dimensi indeks SET. 
Analisis dilakukan pada setiap dimensi indeks pada BUS dari tahun 2011 sampai dengan 2016. Hasil uji tingkat pengungkapan CSR berdasarkan dimensi indeks Shariah Enterprise Theory (SET) dapat dilihat pada tabel 1 berikut:

Tabel 1

Tingkat Pengungkapan CSR berdasarkan Dimensi SET

\begin{tabular}{|c|c|c|c|c|c|c|}
\hline \multirow{2}{*}{ No } & \multirow{2}{*}{ Nama Perusahaan } & \multicolumn{5}{|c|}{ Dimensi SET } \\
\cline { 2 - 6 } & & Allah SWT & Nasabah & Karyawan & Komunitas & Alam \\
\hline 1. & BMI & $100 \%$ & $94 \%$ & $93 \%$ & $94 \%$ & $46 \%$ \\
\hline 2. & BVC & $100 \%$ & $80 \%$ & $80 \%$ & $79 \%$ & $4 \%$ \\
\hline 3. & BRIS & $100 \%$ & $86 \%$ & $92 \%$ & $88 \%$ & $23 \%$ \\
\hline 4. & BJBS & $58 \%$ & $74 \%$ & $78 \%$ & $83 \%$ & $2 \%$ \\
\hline 5. & BNIS & $100 \%$ & $87 \%$ & $90 \%$ & $86 \%$ & $7 \%$ \\
\hline 6. & BSM & $100 \%$ & $89 \%$ & $93 \%$ & $90 \%$ & $31 \%$ \\
\hline 7. & BMS & $100 \%$ & $87 \%$ & $85 \%$ & $86 \%$ & $4 \%$ \\
\hline 8. & BPS & $100 \%$ & $83 \%$ & $88 \%$ & $77 \%$ & $9 \%$ \\
\hline 9. & BSB & $100 \%$ & $87 \%$ & $85 \%$ & $75 \%$ & $9 \%$ \\
\hline 10. & BCAS & $100 \%$ & $86 \%$ & $88 \%$ & $82 \%$ & $6 \%$ \\
\hline 11. & BMSI & $100 \%$ & $83 \%$ & $85 \%$ & $80 \%$ & $9 \%$ \\
\hline 12. & BTPNS & $75 \%$ & $80 \%$ & $75 \%$ & $82 \%$ & $4 \%$ \\
\hline 13. & BAS & $100 \%$ & $57 \%$ & $75 \%$ & $75 \%$ & $7 \%$ \\
\hline
\end{tabular}

Sumber : Data diolah (2018)

Tingkat pengungkapan CSR juga dinilai berdasarkan SET secara kumulatif. Adapun ketentuan predikat tingkat pengungkapan CSR diklasifikan dalam 4 kategori, yaitu : Sangat Informatif (81\% $100 \%)$, Cukup Informatif $(66 \% \leq 81 \%)$, Kurang
Informatif $(51 \% \leq 66 \%)$, dan Tidak Informatif $(0 \% \leq$ $51 \%$ ). Hasil analisis tingkat pengungkapan CSR berdasarkan SET secara kumulatif dapat dilihat pada table 2 berikut:

Tabel 2

Predikat Tingkat Pengungkapan CSR berdasarkan SET

\begin{tabular}{|c|c|c|c|c|c|c|c|c|c|}
\hline \multirow{2}{*}{ No } & \multirow{2}{*}{ Nama Perusahaan } & \multicolumn{6}{|c|}{ Tahun } & \multirow{2}{*}{ Rata- rata } & \multirow{2}{*}{ Predikat } \\
\cline { 2 - 8 } & & 2011 & 2012 & 2013 & 2014 & 2015 & 2016 & & $\begin{array}{c}\text { Sangat } \\
\text { Informatif }\end{array}$ \\
\hline 1. & BMI & $74 \%$ & $84 \%$ & $91 \%$ & $84 \%$ & $88 \%$ & $91 \%$ & $85 \%$ & Informatif \\
\hline 2. & BVC & $49 \%$ & $65 \%$ & $70 \%$ & $67 \%$ & $72 \%$ & $79 \%$ & $67 \%$ & Informatif \\
\hline 3. & BRIS & $70 \%$ & $72 \%$ & $67 \%$ & $81 \%$ & $86 \%$ & $79 \%$ & $76 \%$ & Kurang Informatif \\
\hline 4. & BJBS & $53 \%$ & $58 \%$ & $56 \%$ & $63 \%$ & $67 \%$ & $79 \%$ & $63 \%$ & Informatif \\
\hline 5. & BNIS & $72 \%$ & $72 \%$ & $67 \%$ & $72 \%$ & $77 \%$ & $77 \%$ & $73 \%$ & Informatif \\
\hline 6. & BSM & $74 \%$ & $79 \%$ & $81 \%$ & $81 \%$ & $84 \%$ & $81 \%$ & $80 \%$ & Informatif \\
\hline 7. & BMS & $67 \%$ & $70 \%$ & $67 \%$ & $72 \%$ & $84 \%$ & $77 \%$ & $73 \%$ & Informatif \\
\hline 8. & BPS & $65 \%$ & $74 \%$ & $65 \%$ & $65 \%$ & $72 \%$ & $77 \%$ & $70 \%$ & Informatif \\
\hline 9. & BSB & $65 \%$ & $72 \%$ & $67 \%$ & $65 \%$ & $74 \%$ & $74 \%$ & $70 \%$ & Informatif \\
\hline 10. & BCAS & $67 \%$ & $67 \%$ & $67 \%$ & $72 \%$ & $77 \%$ & $79 \%$ & $72 \%$ & Informatif \\
\hline 11. & BMSI & $70 \%$ & $67 \%$ & $67 \%$ & $72 \%$ & $70 \%$ & $77 \%$ & $71 \%$ & Tidak Informatif \\
\hline 12. & BTPNS & $0 \%$ & $0 \%$ & $0 \%$ & $58 \%$ & $65 \%$ & $70 \%$ & $32 \%$ & Tidak Informatif \\
\hline 13. & BAS & $0 \%$ & $0 \%$ & $0 \%$ & $0 \%$ & $53 \%$ & $60 \%$ & $19 \%$ & \\
\hline
\end{tabular}

Sumber : Data diolah (2018) 


\section{Pengujian Hipotesis dan Pembahasan}

Pengujian hipotesi menggunakan analisis regresi linier berganda mengharuskan data berditribusi normal bebas dari uji asumsi klasik. Hasil pengujian asumsi klasik menunjukan bahwa data berdistribusi normal, bebas dari multikolinieritas dan heterokedastisitas. Sementara hasil pengujian hipotesis melalui regressi linier berganda diperoleh nilai $-3,032$ dengan signifikansi 0,003 yang bermakna bahwa semakin besar total asset sebuah bank tidak motivasi bank untuk melakukan pengungkapan tanggungjwab social perusahaan. sementara nilai ROE $-0,501$ dengan signifikansi 0,618 serta kepatuhan syariah memiliki sebesar 1,216 dengan signifikansi 0,288. Hasil pengujian hipotesis kedua dan ketiga menunjukkan bahwa ROE dan kepatuhan syariah tidak berpengaruh terhadap pengungkapan tanggungjawab social perusahaan.

Hasil pengujian hipotesis menyatakan bahwa total asset bank berpengaruh negative terhadap CSR. Hasil ini tidak sejalan dengan penelitian Novita Febriyani, Inten Meutia dan Suhel (2013) dan Iwan Setiawan et al., (2016) namun dengan arah yang berbeda. Sementara ROE dan Kepatuhan syariah tidak berpengaruh terhadap CSR. Berdasarkan teori yang ada dalam perspektif islam, perusahaan harus bersedia menyajikan informasi secara komprehensif tanpa melihat apakah perusahaan menghasilkan keuntungan atau tidak (Baydon\& Willet, 2000). Laba bukan merupakan pendorong bank untuk melakukan pengungkapan CSR. Hasil penelitian ini sesuai dengan penelitian Novita Febriyani, Inten Meutia dan Suhel (2013) dan Iwan Setiawan et al., (2016), yang menemukan bahwa laba tidak bepengaruh terhadap CSR. Kepatuhan syariah tidak berpengaruh terhadap CSR, hasil ini dapat diinterpretasikan bahwa kepatuhan syariah tidak menjamin bank mengungkan CSR. Hasil ini sesuai dengan Novita Febriyani et. al (2013) dan Amanda Kyka Maharani et. al (2015).

\section{Kesimpulan, Keterbatasan, dan Saran}

Berdasarkan Shariah Enterprise Theory (SET) menunjukan bahwa praktik CSR pada Bank Umum Syariah di Indonesia telah memberikan informasi secara informatif rata-rata sebesar $76 \%$ dari total keseluruhan Bank Umum Syariah, sedangkan sisanya yaitu sebesar 24\% kurang informatif dalam memberikan informasi. Hal tersebut dikarenakan terdapat beberapa Bank Umum Syariah yang belum lama berdiri menjadi Bank Umum Syariah. Terdapat dua bank umum syariah yang mengungkapkan praktek CSR tidak informative dan satu bank sangat informative.

Penelitian ini dilakukan dalam pendekatan kuantitatif sehingga masih terbatas hanya pada unsurunsur pengungkapan CSR yang bersifat voluntary, untuk penelitian selanjutnya disarankan untuk menggunakan pendekatan kualitatif sehingga di peroleh pembahasan yang lebih konfrehensif.

\section{Daftar Pustaka}

Al-Quran dan Terjemahannya. 2014. Jakarta: Departemen Agama RI

Ansori. 2001. Pengungkapan Sharia Compliance dan Kepatuhan Bank Syariah Terhadap Prinsip Syariah.Jurnal Dinamika Akuntansi, Vol 3 No. 2.

Arifin, Zainal. 2009. Dasar-dasar Manajemen Bank Syariah. Tangerang: Aztera.

Belkaoui, Ahmed R. 2001. Teori Akuntansi, Edisi 4, Jilid 2. Jakarta: Salemba Empat.

Febriyani, Novinta., Meutia, Inten., \& Suhel. 2014. Analisis Islamic Social Reporting Pada Bank Umum Syariah di Indonesia. Call of Papers Seminar Nasional \& Silatnas IV FORDEBI. Universitas Sriwijaya.

FS, Erwin. Tanggung Jawab Sosial Bank Syariah. $<$ http://charmindonesia.wordpress.com> [16/04/2017]

Hayzelt, Jeffrey. Why Should Your Business Care About Social Responsibility?[19/11/2017]

Kotler, Philip \& Lee, Nancy R. 2005. Corporate Social Responsibility: Doing the Most Good For Your Company and Your Cause. Hoboken, New Jersey: John Wiley \& Sons, Inc.

Lestari, Puji. 2013. Determinants Of Islamic Social Reporting In Syariah Banks: Case Of Indonesia. International Journal of Business and Management Invention. PP. 28-34.

Mansur, Syuhada. 2012. Pelaporan Corporate Social Responsibility Perbankan Syariah Dalam Perspektif Syariah Enterprise Theory.Economic: Jurnal Ekonomi dan Hukum Islam, Vol.2, No.2.

Meutia, Inten. 2010. Qualiative Approach To Build The Concept of Social Responsibility Disclousure Based On Shari'ah Enterprise Theory. Master of Bussiness Administration. 1634.

Nienhaus, Volker. 2011. Islamic Finance Ethics and Shari'ah Law in the Aftermath of the Crisis: Concept and Practice of Shari'ah Compliant 
Finance. Ethical Prespective 18, N0.4, 591-623

Olifia.41 Perusahaan Peraih ICSRA Indonesia 2017.Melalui<http://economicreviewnews.com> [16/04/2017]

Purnasanti, Maulida Adelhita Pur., Yulianto. Agung, \& Asrori. 2014. Analisis Faktor-faktor yang Memperngaruhi Pengungkapan Islamic Social Reporting (ISR). Makalah Simposium Nasional Akuntansi XVII. Mataram

Republik Indonesia. 2007. Undang-undang RI No.25 Tahun 2007 tentang Penanaman Modal. Jakarta 2007. Undang-undang RI No.40 Tahun 2007 tentang Perseroan Terbatas. Jakarta

Santoso, Arif Lukman \& Dhiyal Ul-Haq. Zaki Murtadho. 2017. Determinan Pengungkapan Islamic Social Reporting pada Bank Umum Syariah di Indonesia. Journal of Accounting and Bussiness Dynamics, vol 4 (2), pp 125-142.

Samsiyah. 2013. Kajian Impelementasi Corporate Social Responsibility Perbankan Syariah Ditinjau Dari Shariah Enterprise Theory Pada PT. Bank Pembiayaan Rakyat Syariah Bhakti Sumekar Cabang Pamekasan. Universitas Trunojoyo: Madura.

Sekaran, Uma \& Roger Bougie. 2013. Research Methods for Business. $6^{\text {th }}$ United Kingdom: John Wiley

Setiawan, Iwan., Faulid Asnawi. Haris, \& Sofyani. Hafiez. 2016. Apakah Ukuran, Profitabilitas, dan Praktik Manajemen Laba Memengaruhi Tingkat Pelasanaan dan Pelaporan Islamic Social Reporting Pada Perbankan Syariah di Indonesia?,Journal of Accounting and Bussiness Dynamics, Vol. 3(2), 2016.

Slamet, M. 2001. Enterprise Theory dalam Konstruksi Akuntansi Syariah (Studi Teoritis pada Konsep Akuntansi Syariah). Skripsi pada Fakultas Ekonomi Universitas Brawijaya.

Untung, Hendrik Budi. 2008. Corporate Social Responsibility. Jakarta: Grafika Offset

Wahyuni, Mirasanti. 2013. Penerapan Akuntansi Islam dan Pelaporan Corporate Social Responsiility Perbankan Syariah. PRESTASI, Vol. 11A No. $1 \mathrm{~A}$.

Yusuf, Yasir. 2010. Aplikasi CSR pada bank syariah: suatu pendekatan maslahah dan Maqasid syariah. EKSIBISI, Vol. 4, No. 2, PP. 98-115.

www.ojk.go.id (diakses 08 April 2017)

www.ifsb.org (diakses 04 Desember 2017) 